\title{
Pseudomonas Mendocina Bacteremia in a Hemodialysis Patient With a Central Venous Catheter
}

\author{
Madeline E. Goldberg $^{1}$, Michelle Blyth ${ }^{2}$, Ed Swiatlo ${ }^{3}$ \\ 1. Internal Medicine-Pediatrics, Tulane University School of Medicine, New Orleans, USA 2. Infectious Diseases, Tulane \\ University School of Medicine, New Orleans, USA 3. Infectious Diseases, VA Medical Center, New Orleans, USA
}

Corresponding author: Madeline E. Goldberg, mgoldberg2@tulane.edu

\begin{abstract}
Pseudomonas mendocina is an uncommon pathogen in humans and there are no documented cases of infection associated with central venous catheters. Here we describe a 72-year-old man on hemodialysis who presented with a fever and was found to have $P$. mendocina bacteremia. The only obvious source of infection was the hemodialysis catheter. The isolate was susceptible to all antibiotics tested and he was successfully treated with ciprofloxacin and central venous catheter removal. Patients with chronic medical conditions and vascular devices are at risk for invasive infections with rare Pseudomonas species. As laboratory pathogen detection advances arise, it is possible that additional cases of Pseudomonas mendocina infections in humans will be identified. Our case provides one example of the successful treatment of Pseudomonas mendocina bacteremia in a 72-year-old man with a line-associated infection.
\end{abstract}

Categories: Internal Medicine, Infectious Disease, Nephrology

Keywords: pseudomonas, psuedomonas mendocina, bacteremia, hemodialysis, esrd, central venous catheter

\section{Introduction}

Hemodialysis catheters are common sources of infection including bacteremia, and they are often needed in patients with end-stage renal disease (ESRD) for renal replacement therapy. Two types of circulatory access most commonly used for renal replacement therapy include arteriovenous fistulas (AVF) and central venous catheters (CVC). CVCs are less desirable as there is a greater risk of infection, however, they are often the best option when vascular access is limited. The relative risk of hospitalization due to infection and subsequent death is two to three times greater for CVCs compared to AVFs [1]. Common organisms implicated in CVC infections include gram-positive cocci such as staphylococci (coagulase-negative as well as Staphylococcus aureus), enterococci, Enterobacteriaceae, and Candida species. In some cases, catheters can be salvaged with catheter exchange over wire or antibiotic lock therapy, however, in most cases of catheter-related bloodstream infection (CRBI) the Infectious Diseases Society of America (IDSA) recommends that the catheter should be removed [2].

Received 08/31/2020

Review began 09/11/2020 Review ended 09/29/2020 Published 10/08/2020

\section{() Copyright 2020}

Goldberg et al. This is an open access article distributed under the terms of the Creative Commons Attribution License CC-BY 4.0., which permits unrestricted use, distribution, and reproduction in any medium, provided the original author and source are credited.

\section{Case Presentation}

This report describes a 72-year-old man who presented to a local hospital with fever and rapid heart rate. Past medical history included: ESRD (on dialysis) caused by immunoglobulin A (IgA) nephropathy; atrial fibrillation (on apixaban); heart failure with reduced ejection fraction (ejection fraction 30-35\%); obesity; and chronic venous stasis of bilateral lower extremities. After the incidental discovery of a fever $\left(102.5^{\circ} \mathrm{F}\right)$ by the patient's home health nurse, the patient was brought to the emergency department (ED). At the ED, patient denied infectious symptoms such as cough, shortness of breath, dysuria, or skin lesions with purulent drainage. Physical exam was notable for chronically edematous lower extremities of equal size with clear weeping. No infected ulcers or areas of erythema and tenderness were noted. Catheter site (right internal jugular vein) was non-tender, non-erythematous, and non-edematous.

The patient was found to have elevated white blood cell (24.33 cells/uL, normal reference values 4.8 - 10.8 cells/uL) and lactic acid ( $3.9 \mathrm{mmol} / \mathrm{L}$, normal reference values $0.5-2.2 \mathrm{mmol} / \mathrm{L})$; in addition, an electrocardiogram demonstrated atrial fibrillation with rapid ventricular response. Chest x-ray showed no consolidations and his urine culture had no growth. Blood cultures were obtained from peripheral sites and the patient was given one dose of vancomycin. The patient was transferred to our hospital and was admitted to the intensive care unit (ICU) for severe sepsis and atrial fibrillation with rapid ventricular rate necessitating an amiodarone drip. Antibiotic coverage was broadened to vancomycin and piperacillin/tazobactam and repeat blood cultures were drawn from peripheral sites as well as the CVC.

Following admission, he was quickly weaned from amiodarone and transferred to the general medicine floor. On day two of admission, peripheral blood cultures from the outside hospital, drawn prior to receiving antibiotics, grew gram-negative rods and vancomycin was discontinued. On day three of admission, these gram-negative rods were identified as Pseudomonas mendocina using matrix-assisted laser 


\section{Cureus}

desorption/ionization-time of flight (MALDI-TOF). The medicine team consulted nephrology, infectious disease, and vascular surgery and all were in agreement that the CVC must be removed. On day four of admission, in vitro susceptibility testing results using microbroth dilution (MicroScan, Beckman Coulter, Inc., Brea, California, USA) were completed. There are no established breakpoints for in vitro susceptibility testing of $P$. mendocina but susceptibility testing of agents commonly used for other Pseudomonas species suggest that this isolate was susceptible to these antibiotics (Table 1).

\begin{tabular}{|l|l|l|}
\hline Antibiotic & Susceptibility & Minimal Inhibitory Concentration (MIC, micrograms per milliliter) \\
\hline Amikacin & Susceptible & $<8$ \\
Tobramycin & Susceptible & $<2$ \\
Gentamicin & Susceptible & $<1$ \\
Meropenem & Susceptible & $<1$ \\
Ciprofloxacin & Susceptible & $<0.5$ \\
\hline
\end{tabular}

\section{TABLE 1: P. mendocina Antibiotic Susceptibility}

apresumptive, as there are no established standards for in vitro susceptibility testing of $P$. mendocina.

Based on testing which showed a minimum inhibitory concentration (MIC) $<0.5$ for ciprofloxacin, antibiotic therapy was de-escalated to ciprofloxacin monotherapy. On day five of admission, the CVC was removed for a 48-hour line-free period. Oral ciprofloxacin was continued throughout this time and a new dialysis catheter (right chest wall trialysis catheter) was inserted on day eight of admission. Patient was discharged that same day after dialysis and completed oral ciprofloxacin at home for a total of 14 days. Patient was discharged home with home health services and with follow-up appointments with primary care, vascular surgery, and nephrology. Blood cultures collected at our facility remained negative throughout his hospitalization.

\section{Discussion}

P. mendocina, a gram-negative, non-fermentative bacillus, was discovered in 1970 in Mendoza, Argentina from soil and water [3]. It is an uncommon pathogen in humans. Since its identification, there have been 14 reported cases of $P$. mendocina infections in humans. Four cases presented with meningitis, five with endocarditis, and two with bacteremia. The remaining cases included peritonitis, septic arthritis, and spondylodiscitis (Table 2). The present case is the fifteenth case of P. mendocina infection reported globally and the third case in the United States. To our knowledge, this is the first reported case of P. mendocina CVC line-associated infection. 


\section{Cureus}

\begin{tabular}{|c|c|c|}
\hline $\begin{array}{l}\text { Publication } \\
\text { Year }\end{array}$ & Location & Description \\
\hline 1992 & Argentina & 63-year-old man with prosthetic aortic valve with native mitral valve endocarditis [6]. \\
\hline 2001 & Denmark & 28-year-old female with situs inversus with native tricuspid valve endocarditis [8]. \\
\hline 2005 & Taiwan & 65-year-old man with alcohol hepatitis and chronic kidney disease with spondylodiscitis [7]. \\
\hline 2007 & Turkey & 36 -year-old man with native mitral valve endocarditis $[9]$. \\
\hline 2011 & France & 79-year-old female with atrial fibrillation with native aortic valve endocarditis [10]. \\
\hline 2011 & Israel & 31-year-old man with bacteremia [5]. \\
\hline 2013 & Singapore & 34-year-old man with motor vehicle accident and foot wound infection leading to septic arthritis [11]. \\
\hline 2016 & States & 57-year old man with chronic alcohol use with native mitral valve endocarditis [12]. \\
\hline 2017 & Portugal & 22-year-old man with peritoneal dialysis with peritonitis [13]. \\
\hline 2018 & Taiwan & 55-year-old man with diabetes with meningitis [14]. \\
\hline 2018 & Taiwan & 66-year-old female with external ventricular drain with meningitis [14]. \\
\hline 2018 & Taiwan & 79-year-old man with chronic obstructive pulmonary disease with meningitis [14]. \\
\hline 2018 & Taiwan & 78-year-old female with meningitis [14]. \\
\hline $201 \mathrm{~S}>\mathrm{C}$ & $\begin{array}{l}\text { United } \\
\text { States }\end{array}$ & $\begin{array}{l}\text { 63-year-old man with human immunodeficiency virus/acquired immunodeficiency syndrome with bacteremia } \\
\text { [4]. }\end{array}$ \\
\hline This study & United Sates & 72-year-old man with end-stage renal disease on hemodialysis with bacteremia. \\
\hline
\end{tabular}

TABLE 2: P. Mendocina Cases

Each case of $P$. mendocina has unique details of presentation and treatment. In 2019, a case of $P$. mendocina bacteremia was reported in a patient with HIV who presented with fever, elevated lactate, and elevated white blood cell count. This patient was successfully treated with ceftazidime [4]. Another case of bacteremia occurred in a young man with $P$. mendocina bacteremia that was presumed to have been acquired from his pet bird's drinking water [5]. A case of $P$. mendocina endocarditis occurred in a florist who the authors surmised acquired the bacterium from a cut contaminated by soil leading to bacteremia and hematogenous spread to the heart [6]. Lastly, P. mendocina has caused localized infection in the spine likely by hematogenous spread from a break in the skin and exposure to contaminated water or soil. This patient improved with source control and cefepime followed by oral ciprofloxacin [7].

Unfortunately, we are unable to definitively confirm the CVC as the source of infection in the present case, as the catheter was grossly contaminated during removal and thus the tip was not sent for culture. We can surmise that this was the most likely source of infection, as the physical exam did not suggest any other source of infection, and no other signs or symptoms were reported consistent with another infection. We believe at some point this patient's catheter site was exposed to contaminated soil or water which led to his infection.

Although there have been only 15 documented cases of $P$. mendocina infection in humans, it is possible that this number will rise as diagnostic advances such as mass spectrometry, polymerase chain reaction (PCR), and next-generation sequencing become widely deployed. These molecular assays allow the characterization of bacteria at a fine level of detail not possible with earlier phenotypic methods. This case adds to the literature as it presents an uncommon Pseudomonas species and catheter-associated infection and will help inform clinical approaches to P. mendocina infection in humans.

\section{Conclusions}

P. mendocina is a gram-negative rod that has been isolated from environmental sources such as water and soil. It is seldom recovered from humans. This is the 15 th case of $P$. mendocina infection in humans and is the first documented CVC line-associated infection. This case adds to the current literature by describing $P$. mendocina bacteremia in a patient with sepsis and the most likely source of infection was the CVC used for dialysis. Although not ideal, many patients require CVC and when patients develop line-associated catheter infections with Pseudomonas species, the IDSA currently recommends the removal of the catheter. This 
patient was successfully treated with catheter removal, followed by a 48-hour line-free period, replacement of a new catheter, and a 14-day course of oral ciprofloxacin based on in vitro susceptibility testing.

\section{Additional Information \\ Disclosures}

Human subjects: Consent was obtained by all participants in this study. Conflicts of interest: In compliance with the ICMJE uniform disclosure form, all authors declare the following: Payment/services info: All authors have declared that no financial support was received from any organization for the submitted work. Financial relationships: All authors have declared that they have no financial relationships at present or within the previous three years with any organizations that might have an interest in the submitted work. Other relationships: All authors have declared that there are no other relationships or activities that could appear to have influenced the submitted work.

\section{References}

1. Dhingra RK, Young EW, Hulbert-Shearon TE, Leavey SF, Port FK: Type of vascular access and mortality in U.S. hemodialysis patients. Kidney Int. 2001, 60:1443-1451. 10.1046/j.1523-1755.2001.00947.x

2. Mermel LA, Allon M, Bouza E, et al.: Clinical practice guidelines for the diagnosis and management of intravascular catheter-related infection: 2009 update by the Infectious Diseases Society of America. Clin Infect Dis. 2009, 49:1-45. 10.1086/599376

3. Palleroni NJ, Doudoroff M, Stanier RY, Solánes RE, Mandel M: Taxonomy of the aerobic pseudomonads: the properties of the Pseudomonas stutzeri group. J Gen Microbiol. 1970, 60:215-231. 10.1099/00221287-60-2215

4. Gani M, Rao S, Miller M, Scoular S: Pseudomonas mendocina bacteremia: a case study and review of literature. Am J Case Rep. 2019, 20:453-458. 10.12659/ajcr.914360

5. Nseir W, Taha H, Abid A, Khateeb J: Pseudomonas mendocina sepsis in a healthy man . Isr Med Assoc J. 2011, 13:375-376. 10.12659/AJCR.914360

6. Aragone MR, Maurizi DM, Clara LO, Navarro Estrada JL, Ascione A: Pseudomonas mendocina, an environmental bacterium isolated from a patient with human infective endocarditis. J Clin Microbiol. 1992, 30:1583-1584. 10.1128/jcm.30.6.1583-1584.1992

7. Chi CY, Lai CH, Fung CP, Wang JH: Pseudomonas mendocina spondylodiscitis: a case report and literature review. Scand J Infect Dis. 2005, 37:950-953. 10.1080/00365540500263177

8. Johansen HK, Kjeldsen K, Høiby N: Pseudomonas mendocina as a cause of chronic infective endocarditis in a patient with situs inversus. Clin Microbiol Infect. 2001, 7:650-652. 10.1046/j.1198-743x.2001.00331.x

9. Mert A, Yilmaz M, Ozaras R, Kocak F, Dagsali S: Native valve endocarditis due to Pseudomonas mendocina in a patient with mental retardation and a review of literature. Scand J Infect Dis. 2007, 39:615-616. 10.1080/00365540601071883

10. Suel P, Martin P, Berthelot G, Robaday S, Etienne M, Chibani A: A case of Pseudomonas mendocina endocarditis. Med Mal Infect. 2011, 41:109-110. 10.1016/j.medmal.2010.09.009

11. Chiu LQ, Wang W: A case of unusual Gram-negative bacilli septic arthritis in an immunocompetent patient. Singapore Med J. 2013, 54:164-168. 10.11622/smedj.2013162

12. Rapsinski GJ, Makadia J, Bhanot N, Min Z: Pseudomonas mendocina native valve infective endocarditis: a case report. J Med Case Rep. 2016, 10:275. 10.1186/s13256-016-1057-6

13. Jerónimo TM, Guedes AM, Stieglmair S, Guerreiro R, Laranjo C, Bernardo I, Neves PL: Pseudomonas mendocina: the first case of peritonitis on peritoneal dialysis. Nefrologia. 2017, 37:647-649. 10.1016/j.nefro.2016.11.004

14. Huang CR, Lien CY, Tsai WC, et. al.: The clinical characteristics of adult bacterial meningitis caused by nonPseudomonas (Ps.) aeruginosa Pseudomonas species: a clinical comparison with Ps. aeruginosa meningitis. Kaohsiung J Med Sci. 2018, 34:49-55. 10.1016/j.kjms.2017.08.007 